\title{
Situating social policy analysis: possibilities from quantitative and qualitative GIS
}

Scott Orford and Brian Webb, University of Cardiff 10

Geographic Information Systems (GIS) use maps and spatial analysis as a way of investigating real-world problems. Although traditionally associated with the geographical disciplines, it has since been population density or percentage of children of school age; physical 27 infrastructure, for instance the road network or public transport 28 routes; or the environmental quality of an area, such as the location 29 of parks and green space or the concentration of air pollution. By 30 layering these themes one on top of the other within the GIS digital 31 mapping, it is possible to see how they relate to each other across an 32 area and to produce composite maps that can reveal spatial patterns and 33 relationships. GIS contains tools that allow the data to be manipulated 34 and analysed spatially and statistically so it is possible to determine, for 35 example, how many people live within five minutes' walk of a bus stop 36 or how many children in low-income households live in a particular $\quad 37$ school catchment area. This combination of mapping and spatial 38 analysis makes GIS a powerful tool when researchers are investigating $\quad 39$ how social and economic problems vary across space, how spatial areas $\quad 40$ relate to one another, or how policy interventions may have different 41 outcomes geographically. And as GIS can map and analyse data at a 42 
variety of spatial scales it is possible to investigate problems at the very local level through to the national and international level.

Traditionally, GIS has been a predominately static tool - it emphasises variation across space rather than change over time. This has partly been a reflection of data availability - socioeconomic data collection tends be cross-sectional rather than longitudinal and in terms of mapping, data are usually only available aggregated into predefined geographical areas whose boundaries often change, hampering comparisons between time periods. These areas are usually designed for a particular function (for example wards for electing local councillors) and so often their boundaries do not reflect the underlying structure of the local population or the social process being investigated. This can result in the geographic areas distorting or unduly influencing the display and analysis of the populations and social processes of interest. This is called the Modifiable Areal Unit Problem (MAUP) and it continues to be an innate issue in social applications of GIS. The ecological fallacy (EF) is related to MAUP and occurs when data aggregated to areas are used to make inferences about individuals who live in those areas. So although we may observe that areas which have high unemployment rates may also have high crime rates we cannot say that it is the unemployed that is the cause of crime, merely that the two have an association at that geographical scale. Again, EF, like MAUP, is a reflection that socioeconomic and demographic data geographically referenced to individual persons and households has traditionally not been available in GIS and rather is supplied at some level of geographic aggregation.

But GIS, socioeconomic data and geographical data are all evolving and there is now increasing capabilities for dynamic mapping, interactive mapping and animated visualisations (for example Andrienko et al., 2016) allowing researchers to investigate how spatial patterns and relationships change over time, and in a finer detail, improving the analysis of the outcomes of policy interventions. These and other issues are addressed and reflected upon throughout the chapter. It will argue why GIS is a useful tool for spatial social policy analysis, looking at how maps and mapping can change the way we see and understand spatial relations between people and places. It will discuss how recent innovations in qualitative GIS are opening up the field to new academic and policy areas that benefit from a mixed method approach to understanding social policy. It will provide many examples from across broad policy themes that illustrate the advantages of exploring the impact of social policy from a geographic perspective within the context of maps, mapping and spatial analysis. It concludes with a reflection and discussion of the issues raised in the chapter and 
looks towards the future in terms of how recent innovations and trends 1 could further the use of GIS in the field of social policy. 2

\section{Why is GIS a useful tool for spatial social policy analysis?}

The way in which we 'see' and 'understand' the spatial relationships that exist within the world has changed over the last 50 years (Davoudi and Strange, 2009) and influenced the evolution and use of GIS. GIS is utilised to overlay different datasets in order to not only represent information, as the discipline of cartography typically does, but also to query and analyse the relationship between those different layers of information. Some of the earliest uses of this more dynamic analysis of spatial data date back to the interpretation of health information collected as part of cholera outbreaks in Paris and London. Most famously, in 1854 the London physician John Snow mapped the locations of cholera victims and nearby water sources in Soho to identify a contaminated water pump where concentrations of victims lived. In doing so, he demonstrated the potential analytical capabilities of overlaying different data sources to identify spatial patterns that may not have traditionally been represented and analysed together on the same map (Snow, 1855; Orford, 2005) and he also provided a timely public health intervention by disabling the pump, preventing its further use.

Through the layering of data in computer-assisted environments, modern GIS provides the ability to represent the spatial distribution of people, resources and information in a single, easy to understand map (Wong et al., 2015). These visualisations are useful means to distil large amounts of information into a single image that can be easily understood by a wide range of non-technical audiences, from policy experts, to politicians, to local citizens. Despite improvements in the analytical capabilities of GIS software, it continues to be used more for spatial information visualisation rather than as an analytical tool to support decision making (Gilfoyle and Wong, 1998; Vonk et al., 2005). This is often the result of a lack of technical expertise of individuals within the public and private sector working in the fields of social science, a point which is discussed later. From a social policy point of view, the layering, analysis and visualisation of data can provide an important means of identifying areas for policy intervention (van der Horst, 2007), allocating resources (Ashby and Longley, 2005), understanding long-term trends (Rebel, 2007) or programme evaluation (Fischer and Nijkamp, 1993). Further innovative uses of GIS beyond these mainstays provide a glimpse of how it might add particular value to

3

4

5

6

7

8

9

10

11

12

13

14 
social policy analysis. However, GIS remains a strikingly niche method across the social sciences and largely overlooked with social policy research and practice. Yet, as discussed below, both quantitative and qualitative GIS offer considerable potential for such policy making and analysis, examples of which are highlighted in the next section

As with any methodological field, GIS techniques, thinking and capabilities continue to evolve, opening up new opportunities for rich spatial insights into social policy issues. Increasingly, for example, more traditional quantitative GIS representations of containerised Cartesian spaces are being challenged through attempts to characterise the relationship between places by mapping flows of data - trade, people, finance, information and so on - rather than displaying static representations of place (Orford and Webb, 2017). Most commonly, flow maps are utilised to map commuting patterns of workers, showing how many people travel from home to work (Rae, 2016) in order to understand the functional geographies of cities and regions Figure 9.1. Flow mapping has been used to understand the spatial extent of areas that cross local boundaries in order to demonstrate the need for different governments to coordinate public policy, particularly in relation to infrastructure provision. Yet, conversely, it also holds potential for understanding the isolation of communities, nodes of intense activity, and the interaction, or lack thereof, between prosperous and more deprived areas.

In a similar vein, GIS is being used beyond its positivist origins to support the creation of more qualitative diagrammatic or conceptual maps that draw together a range of secondary data to construct a single, more artistic image of an overall idea. Such a process is useful for defining potential policy problems that need to be addressed or as a baseline for a visioning process to engage different actors about initiatives (Wong, 2006). The process brings together multiple layers of spatial data about a place and then works to analyse and simplify that information into more basic representations of space, such as by identifying core problem areas, key strategic corridors, or relationships between places. In 1989 French geographer Roger Brunet developed a conceptual metaphor of Europe drawn from a range of spatial socioeconomic data and historical information, identifying a 'Blue Banana' (due to its shape and the colour used to map it) stretching from North West England around France's north-eastern border to northern Italy as a means of highlighting the lack of European socioeconomic integration and inequality between European countries (RECLUS, 1989). This simplification of spatial data was not processed through mathematical equations but rather was informed qualitatively by 
Figure 9.1: Tract-to-tract commutes of $80 \mathrm{~km} / 50$ miles or less in the Bay Area, $\quad 1$ California, USA

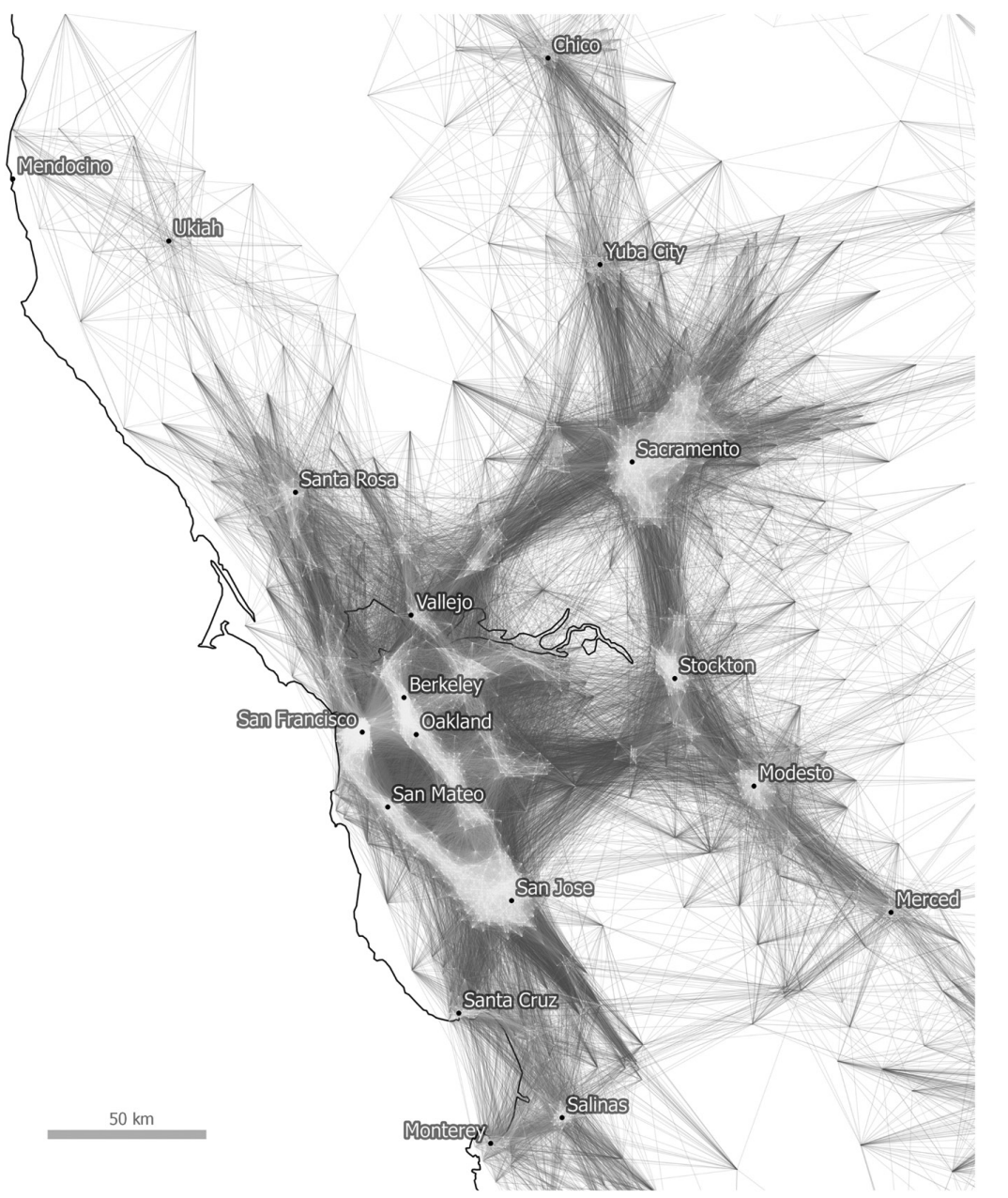

Source: [[does the copyright holder stipulate that the source must be given in full in the credit?]]

individual experiences, value systems and professional norms which interacted to generate a new way of thinking built through social 35 practices rather than positivist representations of space. 36

Furthermore, the last decade has seen various innovative attempts $\quad 37$ to use GIS for qualitative data management and analysis (for example 38 Kwan and Knigge, 2006; Pavlovskaya, 2006[[please provide 39 reference]]; Elwood and Cope, 2009). By adding geo-references to 40 place names within a document, transcript or social media content, for 41 instance, it is possible to use the GIS to map the textual data and add 42 
value and additional insights into the understanding and interpretation of the text. Other types of data promoted by qualitative GIS include photographs, video footage and audio clips that can add depth and context to the statistical data traditionally associated with GIS. Moreover, GPS[[please give in full]] trace data of the movements of people or people's perceptions of the place in which they live collected through cognitive mapping exercises may provide methodologies and approaches that go beyond the static and Cartesian framework of most GIS. Hence qualitative GIS lends itself to those aspects of social policy research that, for example, emphasise the importance of lived experiences when addressing social problems and the effectiveness of policy interventions, or that seeks to identify differences between objective knowledge provided by quantitative GIS data and people's partial, subjective knowledge and experience of place.

\section{Case studies of indicative examples}

The previous section has provided an overview of some of the major ways in which quantitative and qualitative GIS are used and their potential to enrich applied social and policy analysis. This section moves on to provide a broad overview of different examples of social policy research with reference to both quantitative and qualitative GIS. The aim in doing so is to illustrate some of the specific insights and opportunities that such GIS methods can bring to social policy making and analysis.

A common use of GIS in social policy is to research people's ability to access public amenities such as post offices, GP surgeries, libraries, sports facilities, polling stations and good schools (for example Orford et al., 2011; Singleton et al., 2011; Higgs et al., 2015, 2017; Langford et al., 2016). This has important implications for the spatial equity of access with people from poor backgrounds or living in poorer neighbourhoods often finding it more difficult to access essential or good-quality services. It is possible to use GIS to generate a wide variety of accessibility measures from simple straight-line distances, to road network and footpath distances, as well as travel time measures. Increasingly, these metrics include the use of public transport, such as buses and trains, to capture those households which do not have access to private transport. More sophisticated accessibility measures will model the supply as well as the demand for public amenities to reflect competition, congestion and the allocation of scarce resources (for example Langford et al., 2016). These measures have been used as variables in statistical models that have quantified the effects of 
accessibility by different groups of people to different types of 1 amenities. For instance, Figure 9.2 illustrates how voter turnout to 2 local elections in London could be improved by siting polling stations 3 closer to where most voters live in terms of voter density. 4

Another example is to understand the spatial implications of school 5 choice on the educational performance of children in the state school 6 sector. In many Western countries including the UK, parents have 7 a choice as to which state school their children may attend and this 8 can lead to competition for the more popular schools and thus the 9 application of admissions criteria to select students. These criteria 10 usually include catchment areas and distance to school (Singleton et al., 11

Figure 9.2: Percentage differences in the predicted probability of turnout at polling district level when re-siting polling stations at the maximum voter 14 density locations for the 1998 local elections, London Borough of Brent, UK 15

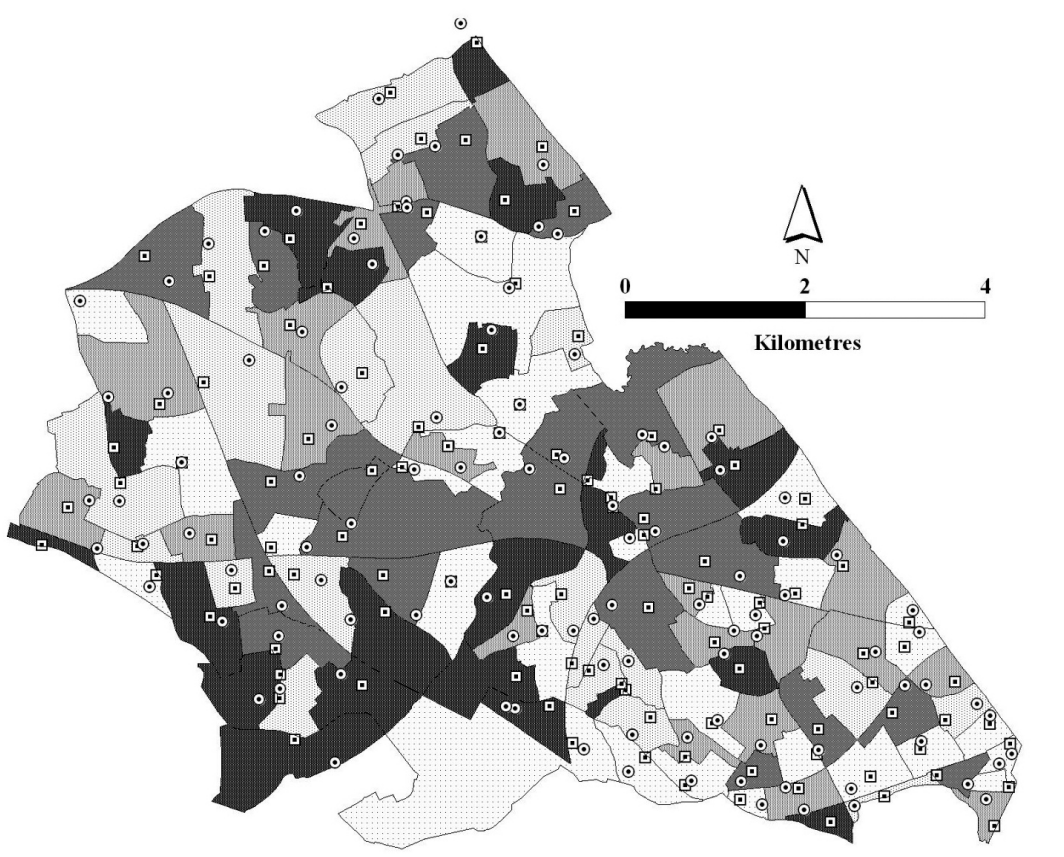

Percentage change in turnout (in quintiles)

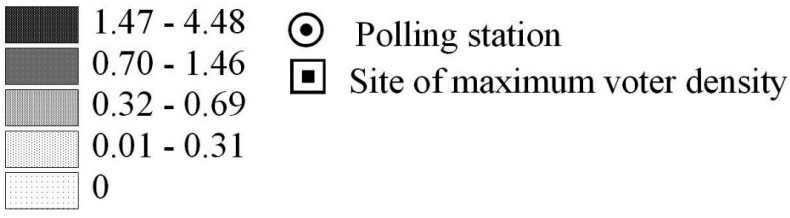


2011) and this can lead to some parents moving close to good schools, pushing up house prices and rents in those local areas (Cheshire and Sheppard, 2004; Glen and Nellis, 2010; Orford, 2018). This 'selection by mortgage' (Harris et al., 2016) can lead to residential sorting of neighbourhoods, reinforcing social class differences and, as a consequence, exacerbating existing inequalities in the state education system. GIS can also be used to model both catchment areas and distance and relate this to educational performance (for example Burgess and Briggs, 2010), income identifiers (such as children in the receipt of free school meals - see Chapter [[chapter 8?]] and also Hamnett and Butler, 2011) and house prices (for example Glen and Nellis, 2010; Orford, 2018).

Accessibility measures have also been used in the construction of the Indexes of Multiple Deprivation (IMD) for England, Scotland and Wales. More broadly, an IMD has been utilised in a number of countries to map and target a range of policy initiatives. This approach divides deprivation into a range of domains that comprise different socioeconomic indicators at different spatial scales. One set of indicators relates to service deprivation measured by GIS analysis of reasonable access to key services using some of the measures outlined above. The domains are then merged and weighted depending on perceived importance to develop a single deprivation ranking of all small areas in a given location (Noble et al., 2006). When mapped, geographical variation in social and economic circumstance between areas becomes apparent and it is often used as a means of understanding the spatial inequality present between places (Figure 9.3). In order to reduce spatial inequality, the measure has been used as a means of targeting funding to places in need as well as for area-based policy initiatives, such as urban regeneration and improvements in service provision (Deas et al., 2003). IMDs have seen particular use to map health inequalities (Mackenzie et al., 1998; Saunders, 1998) and understand factors related to issues such as mortality (Smith et al., 2014), breastfeeding (Brown et al., 2010) and cardiovascular disease (Ramsay et al., 2015).

GIS has also been increasingly utilised to develop geodemographic typologies of places in order to better understand their spatial make-up. Geodemographics are developed by drawing together large amounts of spatial socioeconomic data to identify 'types' of similar areas and classify them based on like characteristics (Vickers and Rees, 2011). Identified areas are often then described based on their overriding features, such as 'Aspiring and Affluent Cosmopolitans', 'Urban and Professional Families' or 'Constrained Ageing City Dwellers'. Such an 
Figure 9.3: Index of Multiple Deprivation Ranking for Manchester, UK at local 1 level super output area level (2015)
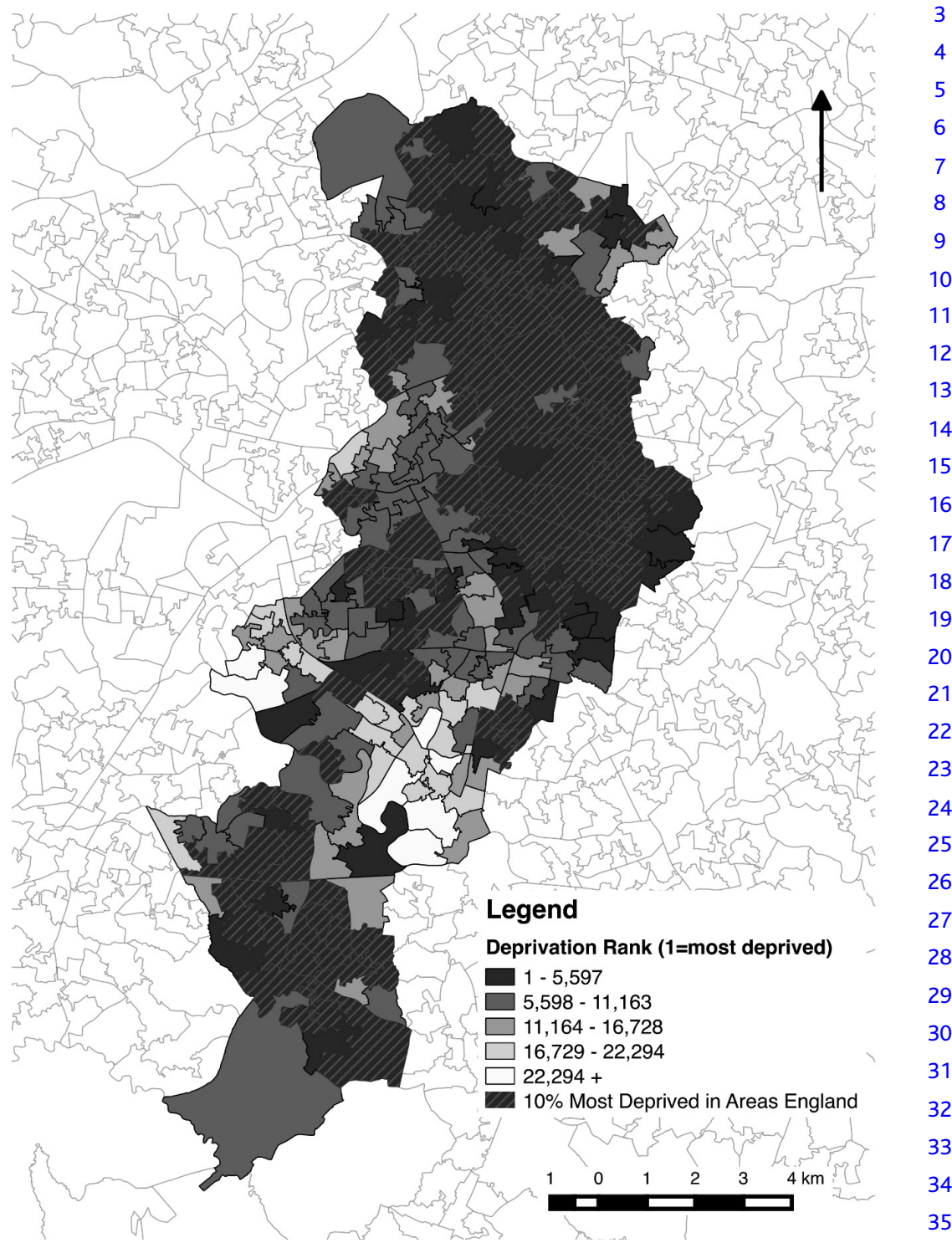

approach stems from the idea that 'where you are says something about $\quad 37$ who you are' (Harris et al., 2005: 2). Whilst this is to some extent 38 inevitably a simplification of complex neighbourhood dynamics, $\quad 39$ such classifications have been widely used in policy and practice, 40 including crime and retail analysis, urban policy and regeneration, 41 through to marketing and environmental management (see Singleton 42 
and Spielman, 2014). Recently, geodemographics have been extended to explore not just the places that people live but also the ways they travel to work. This approach links demographic data to commuting flows, allowing researchers and policy makers to understand not only the number of people commuting between places but also who those people broadly are (ethnicity, occupation, gender, and so on.) and what mode of transportation they use (Hincks et al., 2018). This data has then been linked into an online interactive GIS system, providing users the ability to visualise the flows between places dynamically.

At a more technical level, GIS systems have also been developed to help professional planners and other policy makers to make decisions. These 'Planning Support Systems' (PSS) incorporate a wide range of spatial data about places that they can overlay and manipulate to help them make better informed decisions (Geertman and Stillwell, 2004). Unlike traditional GIS, such systems are customised to the task of decision making, incorporating a range of different components with specifically developed tools, models and analytical capabilities unique to the solving of problems. These systems help decision makers in two main ways, first to identify the problem, its causes and what can be done about it, and second to learn about other stakeholders' views by facilitating the exchange of information between professional as well as lay groups (Pelzer et al., 2014). Examples range from systems that allow the impact of transportation interventions on land use to be modelled (Arampatzis et al., 2004), to measuring and targeting sustainability measures and the potential impact of policy changes (Graymore et al., 2009). A key challenge with these systems stems from the wide range of disciplinary clients, which, as they become more developed and complex, must balance software capabilities with the levels of expertise present among potential users.

In this respect, there are examples of innovative qualitative and participatory GIS within social policy research and practice, reflecting the importance of engagement and participation of community groups and the public within planning, policy and research processes. There has been a tradition of participatory mapping in local government planning as a means of engaging local communities, particularly in the consultation process of local plan and decision making. These tend to use various 'mental mapping' exercises (such as sketch maps) as a means of getting local people to elucidate their thoughts, perceptions, opinions and local knowledge of an area being affected by a planning decision (Cinderby and Forrester, 2005; Dennis, 2006). The spatial representations created through these mapping exercises are digitised and incorporated into the GIS for further analysis. An example of 
participatory mapping is in the analysis of crime and neighbourhood safety. Orford and Leigh (2014) analysed over 700 maps based on residents' perceptions of the neighbourhoods in which they lived and worked in Cardiff, created as part of a wider research project on the role of neighbourhood intelligence in combating crime. The maps were generated by the residents during in-depth interviews using a mobile GIS interface which allowed them to draw neighbourhood boundaries onto a digital base map and annotate the map with insights and knowledge about their neighbourhood (Figure 9.4). This allowed maps of different crimes to be analysed with respect to resident-defined neighbourhoods and revealed the importance of local knowledge in explaining patterns and occurrences of crime at different times of the day and night. Other examples include the work by Pain and colleagues (2006), who found that crime hotspots identified by GIS crime data mapping did not match up with residents' experience of crime or their satisfaction with crime prevention measures, such as good street lighting, which has important implications for future policy interventions.

The adoption of GIS in local planning authorities saw a movement away from information gathering solely using participatory mapping approaches to Public Participation GIS (PPGIS), where local communities and citizens are involved in an iterative process before

Figure 9.4: Self-reported neighbourhoods with residential/work locations in Cardiff, UK

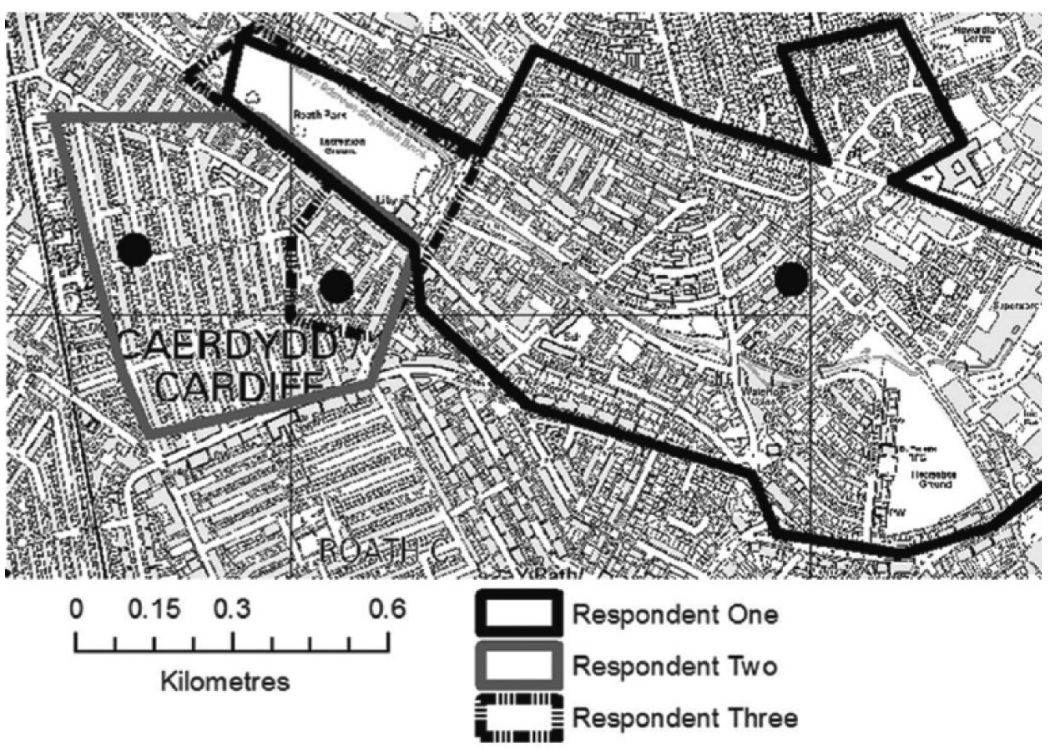


the final maps are produced (Kwan and Ding, 2008). Some of the first usages of more community-based PPGIS in the UK were to engage communities in local problem identification. For example, in the 'Shaping Slaithwaite' project residents of the West Yorkshire village were asked at a local fair to contribute to ideas about ways to improve their village. As part of this, computers were provided and an online interactive GIS system of the local area was created. Residents were asked to interact with the online map and leave comments about the different places, such as what areas should be developed or protected or what a particular building means to them, which were then fed into the local planning process (Kingston et al., 2000). At a larger scale, a woodland regeneration in the Yorkshire Dales National Park Authority also highlighted the early potential of PPGIS by allowing users to interact with an online map to select relevant factors to consider for an expansion in woodland tree planting and weighting their importance to generate different possible scenarios and preferred options (Carver et al., 2001).

Despite their democratic, policy and analytical appeal, there is however a potential danger with such approaches as projects may be based on explanatory information and maps that support the arguments of the planning authority rather than those of the communities involved and does nothing to address the inherent power relations in the decision-making process (Perkins, 2007). It is therefore necessary to carefully consider how such systems are designed and for whom. With the advent of Web 2.0 and neogeography (Haklay et al.[[ok changed to match reference]], 2008) citizens increasingly have the opportunity to become more involved with the collection, analysis and presentation of mapping data than in PPGIS in a field referred to as GeoParticipation (Panek, 2016). Here new (and often free) geospatial technologies such as GPS receivers on smart phones allow members of the public to generate and analyse their own maps and upload them onto online community sites to allow others to engage with them without the constraints imposed by official organisations. Probably the best example is OpenStreet Map (OSM) but others include FixMyStreet, by the charity mySociety, which makes it easier for people to report problems in their local community via a map-based platform. Less formal is EmoMap (Ortag and Huang, 2011; Gartner, 2012) that allows local people to map their emotions about particular places using a smart phone app and make them publicly available online. This can be used to visualise the way people feel about different parts of their local community which could form an additional layer of information for planners and decision makers. GeoParticipation is 
a call for a more humanised approach to mapping information and 1 technology in an attempt to democratise the spatial decision-making 2 process of planners and policy makers (Panek, 2016). The results of 3 these different types of participatory mapping are often the reflections 4 of the social and cultural backgrounds of the communities and their 5 understanding of spaces and spatial relations (Corbett and Rambaldi, 6 2009).

In a related field, geo-narrative is a GIS-based approach to narrative 8 analysis based on oral histories, life histories and biographies (Kwan 9 and Ding, 2008). Here GIS is used to handle, visualise and analyse 10 the chronology of people's experiences and the sequence of events. 11 An example of this is research into the lives of 37 Muslim women in 12 Columbus, Ohio, US in 2002 and the effects of the 9/11 attacks in 13 terms of hostility and hate crimes (Kwan, 2008). The life paths of the 14 37 women were generated in the GIS based on a variety of multimedia 15 data, including: survey diaries about activities and trips undertaken on 16 designated days; oral histories through in-depth interviews based on 17 how their lives had changed post-9/11 and their perception of safety 18 and risk of where they lived; sketch maps of neighbourhoods including 19 areas which they considered unsafe before and after 9/11; and photos 20 and voice clips to contextualise their experiences. The life paths and 21 associated geo-narratives of the women's lives revealed that space and 22 time played a significant role in shaping the participants' post-9/11 23 experiences and that specific spatial and temporal experiences and 24 events could be identified that were common to several of the women. 25

Finally, a slightly different example of qualitative GIS in social policy 26 research comes from Orford and Webb (2017) and their mapping of 27 social policy areas identified from the daily working practices of public 28 policy practitioners in Wales. Here practitioners were interviewed 29 in depth about their daily working lives and were encouraged to 30 talk about the places that were significant in their activities. These 31 places were geo-referenced and then mapped using spatial ellipses 32 (Alexander et al., 2011) as a way of aggregating the individual places 33 into regions. Different maps were produced for different policy areas 34 and these were overlaid to compare and contrast how practitioners 35 working in different fields had different activity spaces even though 36 they may work for the same local authority and be based in the same 37 location (Figure 9.5). The maps identified core and peripheral areas 38 of working in the local authority which did not necessarily match up $\quad 39$ with the practitioners' official job demarcations and instead reflected 40 historic ties with former administrative areas long since abolished and 41 collaborations with new organisations. They emphasise the fuzziness in 42 
3

4

5

6

7

8

9

10

11

12

13

14

15

16

17

18

19

20

21

22

23

24

25

26

27

28

29

30

31

32

33

34

35

36

37

38

39

40

41

42

Figure 9.5: Spatial ellipses of stakeholder interviews by policy area for North Wales, UK

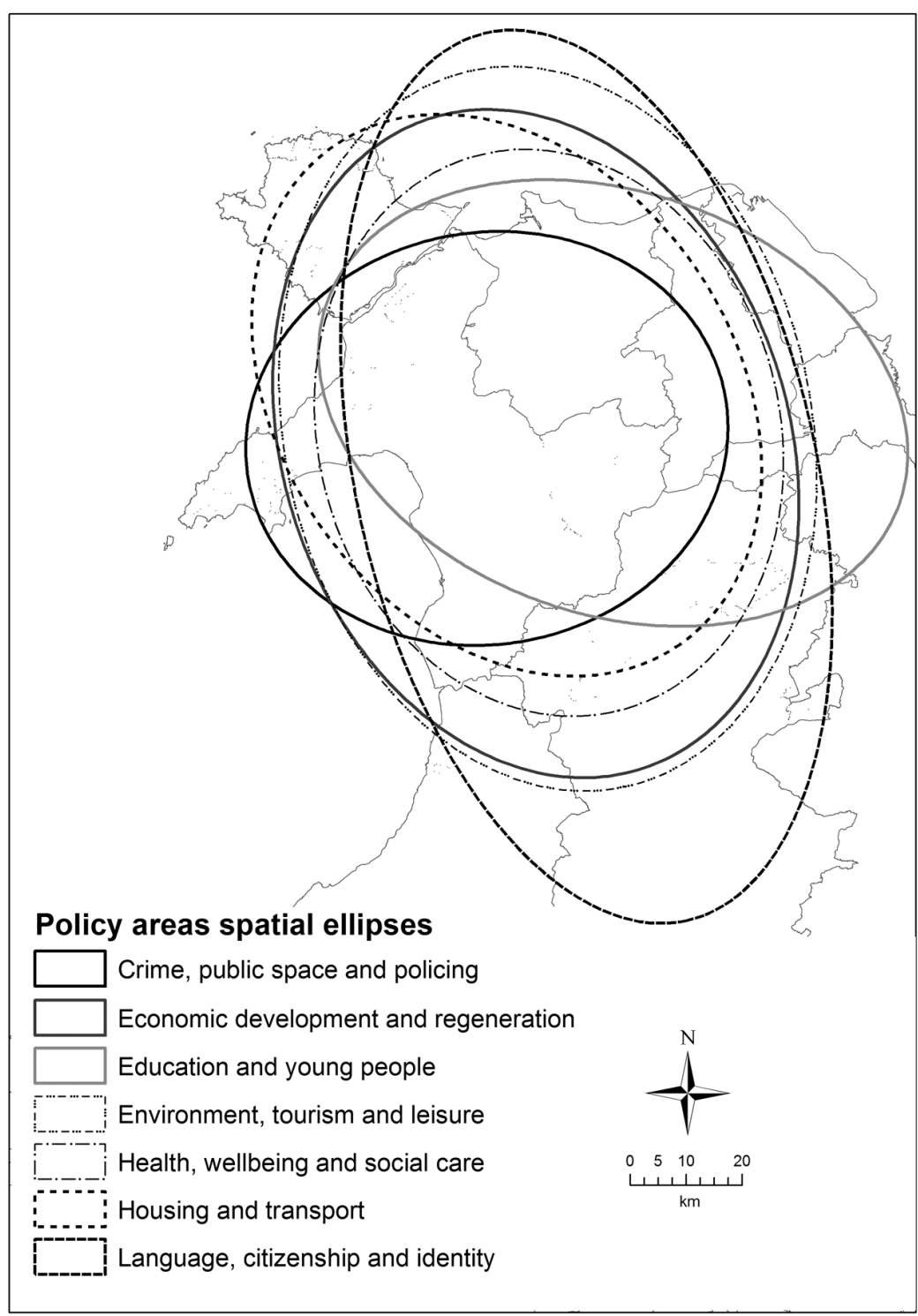

the spatial working practices of policy practitioners and how these are difficult to change even with the implementation of new geographic regimes. 


\section{The future of GIS in social policy and analysis}

This final section looks towards the future of GIS in social policy

and analysis and briefly discusses continuing challenges and some developments that may help address these issues. Traditionally there have been many barriers to the adoption of GIS in social research and policy fields (for example Göçmen and Ventura, 2010). These include the costs of hardware and software, the costs and availability of data, knowledge and awareness of what GIS can do within an application domain, and the training and skills to use the GIS. Over the years some of these barriers have been reduced or removed entirely, whilst others remain in place. GIS software now runs on a standard PC or laptop and the emergence of free and open-source software such as QGIS means that significant financial costs have been removed. Spatial data, such as digital boundary data, are increasingly available under Open Data licence agreements (including UK Ordnance Survey data), whilst many government statistical data sources have standardised geographical references associated with their data records and are available on open platforms (such as data.gov and data.gov.uk).

However, there are many types of data that social policy researchers may find useful, such as survey or administrative data records, where the geographical references may not be of good quality or non-existent and mapping of the data remains problematic (see Fry et al., 2017, and Bright et al., 2018, for recent commentaries on the issues of mapping alcohol licence records collected by local authorities and alcohol outlets available from OSM respectively). Added to this is the general rule of thumb that the more fine-grained the spatial data the less likely it is to be current and the fewer types of data that are available. The quantity, variety and currency of social policy data are far higher for large geographical areas such as government regions and local authorities/municipalities than for small areas such as neighbourhoods, wards and census tracts. This can impact the viability of GIS in social policy research if the objective is to monitor and evaluate the effect of policy interventions in a timely manner at small spatial scales such as within cities or neighbourhoods.

There can be complex privacy and ethical issues associated with mapping data relating to people of interest in social policy research, such as vulnerable children or people with mental health problems, which can either prevent the use of GIS or impede analysis. Maps can hide as well as reveal people and their relationships with places (Dorling and Fairbairn, 1997). Vulnerable or minority groups are either often hidden in the detail of the maps or missing altogether. 
This is partly because these groups are missing from the data records (for example homeless persons) or they appear in numbers so small that they are redacted due to data disclosure issues or vanish when aggregated into larger populations. Mapping can be a disclosive act in itself - showing where a person or group of people live can often identify them and therefore the publication of a map may be restricted or the data obscured in some way.

Nevertheless, despite these technical and ethical challenges, arguably the largest barrier to the uptake of GIS in social policy research concerns the knowledge of what GIS can offer and the training and skills to undertake the research. GIS education and training tends to be focused within particular disciplines in universities (Harris et al., 2014) and not necessarily those disciplines associated with social policy research. Within government organisations, GIS tends to be a function of particular teams (for instance, in Planning) as oppose to being embedded throughout the organisation, and this is particularly true of smaller organisations. The result is that the people with the GIS knowledge and skills are not necessarily working within social policy research teams and this limits the application of GIS in this domain.

There are several developments in GIS and the social policy data landscape that could have positive impacts on the use of GIS in social policy research. The first is the emergence of Big Data and linked data especially around administrative datasets. Big Data not only refers to the enormous size of some social datasets that now exist, or their completeness in terms of population-level data, but also to the use of machine learning to undertake predictive analysis of user behaviour to find correlations between different socioeconomic processes in different geographical environments. In social policy this has been used for example to identify patterns in crime rates, disease prevention, and understanding how different types of people move around areas at different times of the day. Coupled to this is the new types of data becoming available gathered by cheap and numerous devices such as mobile devices (such as smart phones), wireless sensor networks (such as for capturing movement of people) and CCTV cameras, as well as social media outputs such as Twitter feeds, that can provide live or near-live information on people and places. These data can have an associated geographical reference enabling them to be mapped and analysed within GIS and have the potential to inform social policy research.

The second development is the Open Data movement which encourages organisations and agencies that collect and host data, including government, to make these more accessible to researchers. 
In the UK, the Economic and Social Research Council (ESRC) have 1 funded a series of Big Data Research Centres whose aim is to facilitate the promotion, access and use of data collected by government and other organisations by academic and policy researchers. Centres include the Administrative Data Research Centres in the four nations of the UK - which deal with data relating to health and social security records, benefits and tax records and crime and justice records - the Business and Local Government Data Research Centre and the Consumer Data Research Centre which allows access to government and commercial data. The centres provide facilities to link data from different datasets to individuals and provide safe settings in which to analyse the data. It is likely that the types of data made available via the Research Centres would be valuable for social policy research and may address some of the issues discussed earlier associated with ethics, privacy and disclosure as well as the currency and availability of data for small areas. Furthermore, accessing data geographically referenced to individuals and households may be one way to address MAUP as this allows data to be aggregated to bespoke areas that better reflect the underlying population and social processes being investigated.

The final development concerns the increasing pervasiveness of GIS technology and spatial data within social science and related research (partly reflecting the 'spatial turn' in the social sciences) and also within the policy and civil society spheres. As GIS, and in particular mapping technology, becomes more prevalent, social policy researchers and the groups they research may become more spatially literate and start to use maps and spatial analysis more in their research. A good example of this is the gradually increasing uptake of open source GIS software and the development of qualitative GIS which is slowly being adopted into new academic and policy areas that have previously viewed GIS as inaccessible, unfamiliar or even inappropriate. However, qualitative GIS is still emerging and it lacks the suite of analytical tools and processes available for traditional GIS applications. There remain challenges with geo-referencing qualitative data, particularly textual data where spatial references may be encoded using descriptions such as 'close to where I live' or 'in the neighbouring town' or 'far away from here' or use vernacular place names that may not exist in official gazetteers. Recent developments in natural language processing, fuzzy matching and querying, and crowd-sourced mapping products such as OSM are helping here though and GIS software packages are now better at handling qualitative data records.

To conclude, GIS and the socioeconomic data landscape are evolving, and increasingly the field has a lot to offer to social policy. 
Innovations in qualitative GIS have allowed a more mixed-method approach, better suited to social policy research with its emphasis on understanding lived experiences and also evaluating the impact of policy interventions. New mapping techniques that emphasise flows of people, trade, ideas, and so on, allow maps to move away from the limited view of containerised Cartesian space whilst dynamic and interactive mapping challenges the static view of GIS and opens up temporal and well as spatial analysis of policy outcomes. Increasing access to micro-level and population-level data sources through open data and Big Data initiatives can start to address some of the concerns of sample size, data currency, MAUP and EF in relation to policy analysis whilst the increasing pervasiveness of maps and mapping in the social sciences and beyond means that geographical methods and ways of thinking are becoming more salient in the policy arena.

\section{References}

Alexander, B., Hubers, C., Schwanen, T., Dijst, M. and Ettema, D. (2011) Anything, anywhere, anytime? Developing indicators to assess the spatial and temporal fragmentation of activities. Environment and Planning B: Planning and Design 38: 678-705.

Andrienko, G., Andrienko, N., Dykes, J., Kraak, M.J., Robinson, A. and Schumann, H. (2016) GeoVisual analytics: interactivity, dynamics, and scale. Cartography and Geographic Information Science 43(1): 1-2.

Arampatzis, G., Kiranoudis, C., Scaloubacas, P. and Assimacopoulos, D. (2004) A GIS-based decision support system for planning urban transportation policies. European Journal of Operational Research 152(2): 465-475.

Ashby, D. and Longley, P. (2005) Geocomputation, geodemographics and resource allocation for local policing. Transactions in GIS 9(1): 53-72.

Bright, J., De Sabbata, S., Lee, S., Ganesh, B. and Humphreys, D.K. (2018) OpenStreetMap data for alcohol research: reliability assessment and quality indicators. Health and Place 50: 130-136.

Brown, A., Raynor, P., Benton, D. and Lee, M. (2010) Indices of Multiple Deprivation predict breastfeeding duration in England and Wales. European Journal of Public Health 20(2): 231-235.

Burgess, S. and Briggs, A. (2010) School assignment, school choice and social mobility. Economics of Education Review 639-649. [[please provide volume number]] 
Carver, S., Evans, A., Kingston, R. and Turton, I. (2001) Public 1 participation, GIS, and cyberdemocracy: evaluating on-line spatial 2 decision support systems. Environment and Planning B: Planning and 3 Design 2001(28): 907-921.

Cheshire, P. and Sheppard, S. (2004) Capitalising the value of free 5 schools: the impact of supply characteristics and uncertainty. Economic 6 Journal 144: 397-424.

Cinderby, S. and Forrester, J. (2005) Facilitating the local governance 8 of air pollution using GIS for participation, Applied Geography 25: 9 $143-158$.

Corbett, J. and Rambaldi, G. (2009) Geographic information 11 technologies, local knowledge and change. In Elwood, S. and Cope, 12 M. (eds) Qualitative GIS. London: Sage, 75-93.

Davoudi, S. and Strange, I. (eds) (2009) Conceptions of Space and Place in 14 Strategic Spatial Planning. London: Routledge (RTPI Library Series). 15

Deas, I., Robson, B., Wong, C. and Bradford, M. (2003) Measuring 16 neighbourhood deprivation: a critique of the index of multiple 17 deprivation. Environment and Planning C: Politics and Space 21(6): 18 883-903.

Dennis, S. (2006) Prospects for qualitative GIS at the intersection of 20 youth development and participatory urban planning. Environment 21 and Planning A 38(11): 2039-2054. 22

Dorling, D. and Fairbairn, D. (1997) Mapping Ways of Representing the 23 World. London: Longman. 24

Elwood, S. and Cope, M. (2009) Qualitative GIS: A Mixed Method 25 Approach. London: Sage. 26

Fischer, M. and Nijkamp, P. (1993) Geographic Information Systems, 27 Spatial Modelling and Policy Evaluation. Berlin: Springer-Verlag. 28

Fry, R., Rodgers, S., Morgan, J., Orford, S. and Fone, D. (2017) Using 29 routinely collected administrative data in public health research: $\quad 30$ geocoding alcohol outlet data. Applied Spatial Analysis and Policy 10: 31 301-315. 32

Gartner, G. (2012) Putting emotions on maps - the wayfinding 33 example. mountaincartography.org: 61-65.[[please provide full 34 reference details]] 35

Geertman, S. and Stillwell, J. (2004) Planning support systems: an 36 inventory of current practice. Computers, Environment and Urban 37 Systems 28: 291-310. 38

Gilfoyle, I. and Wong. C. (1998) Computer applications in planning: $\quad 39$ twenty years' experience of Cheshire County Council. Planning 40 Practice and Research 13(2): 191-197. 41 
Glen, J. and Nellis, J.G. (2010) 'The price you pay': the impact of state-funded secondary school performance on residential property values in England. Panoeconomicus 4: 405-428.

Göçmen, Z.A. and Ventura, S.J. (2010) Barriers to GIS use in planning. Journal of the American Planning Association 76: 172-183.

Graymore, M., Wallis, A. and Richards, A. (2009) An index of regional sustainability: a GIS-based multiple criteria analysis decision support system for progressing sustainability. Ecological Complexity 6(4): 452-462.

Haklay, M., Singleton, A. and Parker, C. (2008) Web mapping 2.0: the neogeography of the GeoWeb. Geography Compass 2, 2011-2039.

Hamnett, C. and Butler, T. (2011) 'Geography matters': the role distance plays in reproducing educational inequality in East London. Transactions Institute of British Geographers 36: 479-500.

Harris, R., Sleight, P. and Webber, R. (2005) Geodemographics, GIS and Neighbourhood Targeting. Chichester: Wiley.

Harris, R., Tate, N., Souch, C., Singleton, A., Orford, S., Keylock, C., Jarvis, C. and Brunsdon C. (2014) Geographers count: a report on quantitative methods in geography. Enhancing Learning in the Social Sciences 6(2): 43-58.

Harris, R., Johnston, R. and Burgess, S. (2016) Tangled spaghetti: modelling the core catchment areas of London's secondary schools. Environment and Planning A 48(9): 1681-1683.

Higgs, G., Langford, M. and Norman, P. (2015) Accessibility to sports facilities in Wales: a GIS-based analysis of socio-economic variations in provision. Geoforum 62: 105-120.

Higgs, G., Zahnow, R., Corcoran, J., Langford, M. and Fry, R. (2017) Modelling spatial access to general practitioner surgeries: does public transport availability matter? Journal of Transport and Health 6: 143-154. Hincks, S., Kingston, R., Webb, B. and Wong, C. (2018) A new geodemographic classification of commuting flows for England and Wales. International Journal of Geographic Information Science 32(4): 663-684.

Kingston, R., Carver, S., Evans, A. and Turton, I. (2000) Web-based public participation geographical information systems: an aid to local environmental decision-making. Computers, Environment and Urban Systems 24: 109-125.

Kwan, M-P. (2008) From oral histories to visual narratives: representing the post-September 11 experiences of Muslim women in the United States. Social and Cultural Geography 9(6): 653-669. 
Kwan, M.-P. and Ding, G. (2008) Geo-narrative: extending Geographic 1 Information Systems for narrative analysis in qualitative and mixed- 2 method research. The Professional Geographer 60(4): 443-465. 3

Kwan M.-P. and Knigge, L. (2006) Doing qualitative research using 4 GIS: an oxymoron endeavour? Environment and Planning A 38: 5 1999-2002.

Langford, M., Higgs, G. and Fry, R. (2016) Multi-modal two-step 7 $\begin{array}{ll}\text { floating catchment area analysis of primary health care accessibility. } & 8\end{array}$ Health and Place 38: 70-81. 9

Longely, P.A., Goodchild, M.F., Maguire, D.J. and Rhind, W. (2015) 10 Geographic Information Science and Systems, 4th edition. London: Wiley. 11

Mackenzie, I., Nelder, R., Maconachie, M. and Radford, G. (1998) 12

'My ward is more deprived than yours'. Journal of Public Health Medicine 13

20: 186-190. 14

Noble, M., Wright, G., Smith, G. and Dibben, C. (2006) Measuring 15 multiple deprivation at the small-area level. Environment and 16 Planning A 38: 169-185. 17

Orford, S., (2005) Cartography and visualization, in Castree, N. 18 Rogers, A. and Sherman, D. (eds) Questioning Geography: Fundamental 19 Debates. Blackwell, 189-205.[[please provide publisher location]] 20

Orford, S. (2018) The capitalisation of school choice into property 21 prices in the UK: a case study of grammar and non-selective state 22 schools in Buckinghamshire. Geoforum 97: 231-241. 23

Orford, S. and Leigh, C. (2014) The relationship between self-reported 24 definitions of urban neighbourhood and respondent characteristics: 25 a study of Cardiff, UK. Urban Studies 15(9): 1891-1908. 26

Orford, S. and Webb, B. (2017) Mapping the Interview transcript: 27 identifying spatial policy areas from daily working practices. Area, 28 early view DOI: 10.1111/area.12408 [[please provide full details]] 29

Orford, S. Rallings C., Thrasher M. and Borisyuk, G. (2011) Changes 30 in the probability of voter turnout when re-siting polling stations: 31 a case study in Brent, UK. Environment and Planning C, Government 32 and Policy 29: 149-169. 33

Ortag, F. and Huang, H. (2011) location-based emotions relevant for 34 pedestrian navigation. Proceedings of the 25th International Cartographic 35 Conference, Paris, France. [[are more details available? If published 36 please give publisher/editor; if not please give full date of 37 conference]] 38

Pain, R., MacFarlane, R., Turner, K. and Gill, S. (2006) 'When, where, 39 if, and but': qualifying GIS and the effect of streetlighting on crime 40 and fear. Environment and Planning A 38(11): 2055-2074. 41 
Panek, J. (2016) From mental maps to GeoParticipation. The Cartographic Journal 53(4): 300-307.

Pelzer, P., Geertman, S., van der Heijden, R. and Rouwette, E. (2014) The added value of planning support systems: a practitioner's perspective. Computers, Environment and Urban Systems 48: 16-27.

Perkins, C. (2007) Community mapping. The Cartographic Journal 44(2): 127-137.

Rae, A. (2016) The geography of travel to work in England and Wales: extracts from the 2011 Census. Applied Spatial Analysis and Policy 1-17.[[please provide volume number]]

Ramsay, S.E., Morris, R.W., Whincup, P.H., Subramanian, S.V., Papacosta, A.O., Lennon, L. and Wannamethee, S.G. (2015) The influence of neighbourhood-level socioeconomic deprivation on cardiovascular disease mortality in older age: longitudinal multilevel analyses from a cohort of older British men. Journal of Epidemiology and Community Health 69: 1224-1231.

Rebel, M. (2007) Geographic information systems and spatial data processing in demography: a review. Population Research and Policy Review 26(5-6): 601-618.

RECLUS (1989) Les villes europeénnes. DATAR. Montpellier: RECLUS.

Saunders J, (1998) Weighted census-based deprivation indices: their use in small areas. Journal of Public Health Medicine 20: 253-260.

Singleton, A.D. and Spielman, S.E. (2014) The past, present and future of geodemographic research in the United States and United Kingdom. The Professional Geographer 66(4): 558-567.

Singleton, A., Longley, P., Allen, R. and O'Brien, O. (2011) Estimating secondary school catchment areas and spatial equity of access. Computers, Environment and Urban Systems 35: 241-249.

Smith, L.K., Manktelow, B.N., Draper, E.S., Boyle, E.M., Johnson, S.J., and Field, D.J. (2014) Trends in the incidence and mortality of multiple births by socioeconomic deprivation and maternal age in England: population-based cohort study. BMJ Open. doi: 10.1136/ bmjopen-2013-004514 [[are there more details available?]]

Snow, J. (1855) On the Mode of Communication of Cholera, 2nd edition. London: J. Churchill.

Van der Horst, D. (2007) Assessing the efficiency gains of improved spatial targeting of policy interventions; the example of an agrienvironmental scheme. Journal of Environmental Management 85(4): 1076-1087. 
Vickers, D. and Rees, P. (2007) Creating the UK National Statistics 1 2001 output area classification. Journal of the Royal Statistical Society 2 A 170: 379-403. 3

Vonk, G., Geertman, S. and Schot, P.P. (2005) Bottlenecks blocking 4 widespread usage of planning support systems. Environment and 5 Planning A 37(5): 909-924. 6

Wong, C. (2006) Indicators for Urban and Regional Planning: The Interplay 7 of Policy and Methods. London: Routledge. 8

Wong, C., Baker, M., Webb, B., Hincks, S. and Schulze-Baing, 9 A. (2015) Mapping policies and programmes: the use of GIS to 10 communicate spatial relationships in England. Environment and 11 Planning B: Planning and Design 42(3): 1020-1039. 12 
